\title{
Do Ethical Consumers Care About Price? A Revealed Preference Analysis of Fair Trade Coffee Purchases
}

\author{
Chris Arnot, Peter C. Boxall and Sean B. Cash \\ Department of Rural Economy, University of Alberta, 515 General Services Building, \\ Edmonton, Alberta, Canada T6G 2H1 (corresponding author: Sean B. Cash; \\ phone: 780-492-4562; fax: 780-492-0268; e-mail: scash@ualberta.ca).
}

The existing literature on socially responsible purchasing relies heavily on stated preference measures elicited through surveys that utilize hypothetical market choices. This paper explores consumers' revealed purchasing behavior with regard to fair trade coffee and is apparently the first to do so in an actual market setting. In a series of experiments, we investigated differences in consumer responsiveness to relative price changes in fair trade and non-fair trade brewed coffees. In order to minimize the hypothetical bias that may be present in some experimental settings, we conducted our experiments in cooperation with a vendor who allowed us to vary prices in an actual coffee shop. Using a choice model, we found that purchasers of fair trade coffee were much less price responsive than those of other coffee products. The demonstration of low sensitivity to price suggests that the market premiums identified by stated preference studies do indeed exist and are not merely artifacts of hypothetical settings.

La littérature existante sur la consommation responsable repose fortement sur les mesures des préférences déclarées recueillies lors d'enquêtes utilisant des choix hypothétiques. Le présent article examine le comportement d'achat révélé des consommateurs concernant le café équitable et constitue apparemment le premier article du genre à le faire dans le contexte d'un marché réel. Au cours d'une série d'expériences, nous avons examiné les différentes réactions des consommateurs concernant les changements du prix relatif des cafés infusés équitables et classiques (non équitables). Pour minimiser le biais hypothétique qui pourrait exister dans certaines situations expérimentales, nous avons effectué nos expériences en collaboration avec un fournisseur qui nous a donné la permission de modifier les prix dans un véritable café-restaurant. À l'aide d'un modèle de choix, nos résultats ont montré que les consommateurs de café équitable réagissaient beaucoup moins au prix que les consommateurs de café classique. Cette faible sensibilité au prix donne à penser que les primes de marché identifiées dans les études sur les préférences déclarées existent effectivement et qu'elles ne sont pas de simples phénomènes de situations hypothétiques.

\section{INTRODUCTION}

Fair trade products represent a large and growing market sector in Canada and worldwide. These products are goods that are supplied through arrangements that guarantee minimum wages to participating producers. Sales of fair trade coffee, the most popular and longest-established fair trade product, were approximately \$20 million in Canada in 2003 (TransFair Canada 2005). Despite the increasing importance of these and other "socially responsible" products, there are few studies that examine the premiums that Canadian consumers may be willing to pay for goods with socially responsible attributes. Furthermore, the existing literature relies heavily on stated preference 
measures elicited through hypothetical survey techniques (e.g., Loureiro and Lotade 2005). Here, we are concerned with consumers' revealed purchasing behavior with regard to fair trade coffee, and present results of a unique experiment in which a coffee vendor allowed the researchers to investigate the effect of price on individual consumer purchases of fair trade and equivalent conventional products in an actual retail establishment.

The world consumes approximately 2.25 billion cups of coffee per day, with Brazil typically being the world's top coffee producer (Ponte 2002). Historically, coffee prices were supported through International Coffee Agreements, originally brokered by the United Nations. In 1989, these agreements were not renewed. This failure signaled the beginning of significant changes in the world coffee market, even though the agreements were eventually reinstated. The 1990s also saw the expansion of coffee production in African and Asian nations that had not previously produced large coffee quantities. In the late 1990s, Vietnam replaced Colombia in its longstanding role as the second largest producer of coffee. The rapid growth of Vietnam's coffee industry caused the world market price of coffee to drop by 1998. Some observers also believe that these changes resulted in a shift in the market from a fairly balanced producer-consumer relationship to a market dominated by operators in consuming nations. Recent years have seen lower and more volatile coffee prices, and a higher proportion of income generated in the coffee production chain being retained in coffee consuming nations.

In an effort to help coffee farmers in developing countries, alternative trading regimes have been developed. Fair trade is a trading strategy that guarantees producers a "fair" price for their products. Fair trade products are often certified by international bodies (e.g., TransFair, Oxfam) who act as regulators for both importers and producers. These certified products are typically advertised using labels which appear on product packaging. In the case of TransFair-certified coffee, producers are guaranteed a minimum price of U.S. $\$ 1.26$ per pound of coffee sold to fair trade distributors, and a premium of U.S. $\$ 0.05$ per pound if the world market price rises above this minimum price (Raunolds 2000; TransFair Canada 2005). In comparison, 2003 and 2004 average world prices for a pound of coffee were U.S. $\$ 0.52$ and U.S. $\$ 0.62$ per pound, respectively (International Coffee Organization 2005). Importers of fair trade coffee also generally commit to long-term contracts and pay farmers in advance for their coffee. There is evidence that fair trade schemes do result in better livelihoods for participating coffee growers (Bacon 2005). Another result is that these coffees are typically sold to consumers for higher prices than conventional coffees (Fair Trade Federation 2004).

Ethical consumerism involves purchasing decisions that are made with consideration for moral dimensions of how products are produced (Browne et al 2000). To date, most research on ethical consumption decisions has relied upon elicitation of stated preferences. Surveys have been conducted to determine consumers' stated willingness to pay premiums for such ethical goods as certified forest products, organic fresh produce, and fair trade, shade grown, and organic coffees. Pelsmacker et al (2005) found that Belgian consumers were willing to pay a price premium of $10 \%$ for fair trade coffee using a conjoint survey approach. Loureiro and Lotade (2005) used contingent valuation methods to determine that U.S. respondents were willing to pay a premium of $\$ 0.22$ per pound over the regular price of $\$ 6.50$ per pound for fair trade coffee. The same study also estimated price premiums of $\$ 0.20$ and $\$ 0.16$ per pound, respectively, for shade grown and organic coffees. 
There has been limited research done on revealed price premiums for ethical goods. Two such studies were conducted by Bjorner et al (2004), who found that Danish consumers were willing to pay a $13-18 \%$ premium for eco-labeled toilet papers, and Anderson and Hansen (2004) who examined consumers' price responsiveness to eco-labeled plywood products. To the authors' knowledge, no studies have examined the revealed preferences of consumers for fair trade products, such as fair trade coffee.

\section{METHODS}

\section{Data Collection}

The current study involves a series of experiments to investigate the differences in consumers' responsiveness to price changes in fair trade and conventional (i.e., non-fair trade) brewed coffees. In order to minimize the hypothetical bias that may be present in some experimental settings, we conducted our experiments in cooperation with a coffee vendor on a major university campus. This coffee vendor sells freshly roasted and brewed coffee and has been in business on the campus for over 25 years. Conversations with the owner and staff revealed that medium-roast coffees, in particular from Colombia, are the most popular coffees at this location. For about six years, the vendor has also provided a fair trade medium-roast coffee from Nicaragua that is similar in flavor and aroma to the Colombian coffee on offer. These fair trade coffees are clearly labeled as such on the menu boards listing the day's coffee options. In the normal course of business, the daily coffees sold include the two medium roasts (Colombian and the fair trade roast), and conventional light roast, dark roast, and flavored coffees. Other beverages available at this location, such as espresso-based drinks and bottled soft drinks, are not considered in this study. In the normal course of business, all of the daily coffees available are advertised prominently using a large sign over the counter of the store.

The experiment involved adjusting the relative prices of the two medium-roast coffees. This shop normally sells its fair trade coffee at the same price as the conventional varieties on offer. At different times during the study period, the vendor agreed to provide discounts of $\$ 0.10, \$ 0.25, \$ 0.30$, or $\$ 0.50$ per cup. The typical price of the most frequently purchased coffee cup size was $\$ 1.20$, and by applying the discount to only one coffee at a time (either fair trade or Colombian), we created a situation in which the relative prices of the two coffees differed by varying degrees. The vendor also allowed the researchers to post additional signs to prominently display the discount being offered at that time.

A random intercept survey was designed to gather information from individual coffee purchasers. As many coffee purchases are made during short breaks during the day, this survey was necessarily brief in order to minimize non-participation by potential respondents who may not have been able to answer an extensive questionnaire. The sampling procedure involved observing people purchasing brewed coffee and approaching them when they left the counter or while they were adding condiments to their coffee. Respondents were verbally asked a series of questions relating to their gender, affiliation with the university (i.e., staff, student, etc.), daily coffee consumption, and familiarity with the phrase "fair trade coffee." All answers were recorded along with the type of coffee purchased, and the coffee type and amount of discount applied to during the interview period.

In order to provide sufficient variation in the prices, the discounts were adjusted twice during each of the five mornings that the experiment was conducted. In addition, 
data were also collected during periods in which no discounts applied. The number of people interviewed in each sampling period was limited to 100 during each morning of the study ( 50 per discount period), in order to construct a balanced sample.

\section{Econometric Analysis}

Coffee purchases were modeled using random utility theory (RUT), which describes the behavior of consumers making discrete choices in a utility-maximizing framework. To understand the coffee preferences, coffee purchases were combined into three categories: Colombian, fair trade, and "other" (in which the light, dark, and flavored roasts were combined). Using RUT to understand preferences for a particular coffee type, $i$, in the consumer's choice set of three alternatives involves developing an associated utility level conditional on its choice represented by $U_{i}=v_{i}+\varepsilon_{i}$. This conditional indirect utility function is comprised of an objective or deterministic component $\left(v_{i}\right)$ and a random error component $\left(\varepsilon_{i}\right)$. The choice of coffee type $i$ over another alternative $j$ implies that the utility of $i$ is greater than the utility of $j$. Thus, for an individual consumer, the probability $(\pi)$ of choosing coffee alternative $i$ is

$$
\pi(i)=\operatorname{pr}\left\{v_{i}+\varepsilon_{i} \geq v_{j}+\varepsilon_{j} ; \forall j \in C\right\}
$$

where $C$ is the choice set of available coffee alternatives. If the random terms are assumed to be independently distributed Type-I extreme value variates, McFadden (1974) shows that the probability of choosing $i$ takes the form:

$$
\pi(i)=\frac{\exp ^{\mu_{v_{i}}}}{\sum_{j \in C} \exp ^{\mu_{v j}}}
$$

where $\mu$ is a scale parameter.

To utilize this econometric structure, consider each coffee alternative in the choice set to consist of a bundle of $m$ attributes. For alternative $i$, this bundle is denoted $X_{i}$. These attributes are substituted into the deterministic portion of utility and a linear functional form is selected to identify their contribution to utility as follows:

$$
v_{i}=\sum_{k=1}^{m} \beta_{k} X_{i}^{k}+\lambda\left(Y-P_{i}\right)
$$

where $\beta_{k}$ represent the weights or parameters on the $m$ attributes, $Y$ is income, $P_{i}$ is the cost of choosing the alternative, and $\lambda$ represents the marginal utility of income. Because the scale parameter is not estimable in a single set of choice data, convention involves setting $\mu=1$ and the choice probabilities become

$$
\pi(i)=\frac{\exp \left(\sum_{k=1}^{m} \beta_{k} X_{i}^{k}+\lambda\left(Y-P_{i}\right)\right)}{\sum_{j \in C} \exp \left(\sum_{k=1}^{m} \beta_{k} X_{j}^{k}+\lambda\left(Y-P_{j}\right)\right)}
$$


The parameters can be estimated using maximum likelihood techniques (Maddala 1983). In the empirical exercise described below, individual income drops out of the formulation because it would not vary significantly with the coffee type purchased; in essence, purchase probabilities are assumed to be homogeneous of degree 0 in income.

The conditional indirect utility functions for each coffee type $\left(v_{i}\right)$ were created using coefficients estimated from a conditional logit model with a left hand side binary variable representing coffee purchase ( 1 if coffee is purchased and 0 if coffee is not purchased) and right hand side variables describing various attributes of the coffee variety. In this study, we considered Colombian coffee to be the base case. Accordingly, we included an alternative specific constant (ASC) for the fair trade product (FAIRTR $=1$ if fair trade, otherwise 0 ), and a similar ASC for the "other" coffee products (OTHER). We also included a coffee price variable (PRICE) and two price interaction variables where the price of fair trade coffee was multiplied by the fair trade ASC (FTPRICE) and price was multiplied by the ASC on the "other" coffee alternative (OTHPRICE). These additional price variables permit the price effect to vary over coffee types. A second model specification included all of the above, as well as two additional interaction terms between the fair trade ASC and gender (FTFEMALE) and familiarity with the concept of fair trade coffee (FTKNOW). These interaction terms allowed us to isolate the effect of the fair trade brand on consumer coffee preferences. The parameters for the conditional logit models were estimated using LIMDEP software (Greene 2002).

\section{RESULTS AND DISCUSSION}

\section{Demographic Results}

A total of 474 surveys were collected, of which 23 were discarded from the descriptive analysis due to missing values in some survey responses. Table 1 gives a breakdown of respondents' affiliation with the university and gender. It also shows the percentages of each coffee type purchased and the average daily coffee consumption by affiliation and gender. Males constitute just over half of the survey sample (54\%), and the majority of the sample is comprised of staff $(54 \%)$ and students (40\%). Contractors and visitors make up a small proportion of the sample, with $1 \%$ and $5 \%$, respectively. Students purchased fair trade coffee more often than staff $(26.5 \%$ and $17 \%$, respectively), and females purchased fair trade coffee slightly more often than males (23\% and $20 \%$, respectively). One-way ANOVA revealed that the difference in percent purchasing fair trade was significant at the $95 \%$ level for students versus non-students $(F=4.883)$, but not for males versus females $(F=0.568)$. The medium-roast Colombian coffee was by far the most commonly purchased product at $39 \%$, followed by fair trade at $21 \%$ and dark at $19 \%$. It may be reasonable to assume that if there had been no discounts offered, more dark coffee would have been purchased than fair trade during the sampling period, as dark coffee was not discounted during the study.

Other interesting results are that males purchased dark coffee more than twice as often as females, and females purchased flavored coffee more than twice as often as males. There was very little difference between staff and students or between males and females in the average number of cups of coffee consumed each day. 
Table 2. Parameter estimates and standard errors (in parentheses) for two revealed preference brewed coffee choice models

\begin{tabular}{|c|c|c|}
\hline Variable & Model 1 & Model 2 \\
\hline FAIRTR ASC & $-2.7524^{* *}(1.0402)$ & $-4.7319^{* *}(1.2176)$ \\
\hline PRICE & $-2.2313^{* *}(0.5803)$ & $-2.2356^{* *}(0.5844)$ \\
\hline FTPRICE & $1.7919^{*}(0.9650)$ & $1.7791^{*}(0.9827)$ \\
\hline OTHPRICE & $-0.1564(0.1077)$ & $-0.1489(0.1095)$ \\
\hline FTKNOW & & $2.0916^{* *}(0.6019)$ \\
\hline FTFEMALE & & $0.2166(0.2336)$ \\
\hline Log-likelihood & -482.3370 & -460.8566 \\
\hline$\rho^{2}$ & 0.02 & 0.04 \\
\hline Number of observations & 470 & 460 \\
\hline
\end{tabular}

${ }^{*}$ Indicates significance at $p<0.10 ;{ }^{* *}$ Indicates significance at $p<0.05$.

\section{Econometric Results}

Table 2 shows the coefficients and significance of variables estimated in two specifications of the conditional logit model, the latter including the interaction terms FTFEMALE and FTKNOW defined above. Neither of these specifications include a parameter estimate of the OTHER ASC term; including this term introduces high multicollinearity into the model. As the specification including the additional interaction terms (model 2) conforms more closely to theory and also performs better in terms of goodness-of-fit as indicated by log-likelihood and pseudo- $R^{2}$ measures $\left(\rho^{2}\right)$, it was used to calculate the elasticity and probability of choice estimates.

The coefficient on PRICE is negative and highly significant $(p=0.0001)$, which holds with prior expectations that price and probability of purchase would be negatively correlated. The coefficient for the fair trade price interaction is positive and significant at the $10 \%$ confidence level $(p=0.0702)$ and the other price interaction term is negative but insignificant $(p=0.1742)$. The results reported below include this interaction term; the results are almost identical when this coefficient is zeroed out. To correctly interpret the results of the effect of price on fair trade purchase, the coefficients on PRICE and FTPRICE must be added together. When this is done, the positive price effect of the FTPRICE coefficient is less than the negative overall price effect (PRICE), suggesting that price will not be as significant an influence in the purchasing decision for fair trade coffee as it is for purchasing the other types of coffees. In other words, increasing price has significantly less of a negative influence on the probability of purchasing fair trade coffee than Colombian coffee or other varieties. This confirms our expectations that price would have a negative effect on demand for fair trade coffee but with a smaller effect than for non-fair trade coffees.

Using Eq. (2) adjusted to exclude income, at the base price of $\$ 1.20$ the probabilities of buying fair trade, Colombian, or other varieties, aggregated across all survey participants, are $0.2297,0.4201$, and 0.3501 , respectively. Note that these probabilities are very close to the proportion of respondents (last row in Table 1) who were observed to purchase each of the three coffee categories $\left(0.213,0.392\right.$, and $0.395,{ }^{1}$ respectively). 
Table 3. Own- and cross-price elasticities of aggregate purchase probability

\begin{tabular}{lccr} 
& \multicolumn{3}{c}{$\begin{array}{c}\text { \% Change in the aggregate } \\
\text { probability of purchasing }\end{array}$} \\
\cline { 2 - 4 } For a $1 \%$ increase in the price of & Colombian & Fair trade & Other \\
\hline Colombian & -1.5582 & 1.1245 & 1.1245 \\
Fair trade & 0.1261 & -0.4217 & 0.1261 \\
\hline
\end{tabular}

The change in the probability of purchasing a given coffee variety as the price of one of the varieties changes is conveniently expressed in elasticity form. The own-price elasticity of $\pi_{i}$ at a given price $P_{i}$ is given by $\frac{\partial v_{i}}{\partial P_{i}} P_{i}\left(1-\pi_{i}\right)$, and the cross-price elasticity for $\pi_{i}$ as the price of another alternative $P_{j}$ changes is $-\frac{\partial v_{j}}{\partial P_{j}} P_{j}\left(\pi_{j}\right)$ (Ben-Akiva and Lerman 1985; Train 2003). This cross-price elasticity is the same for all $i$; that is, a change in the price of alternative $j$ changes the probabilities of all other alternatives by the same percentage (Train 2003).

From Eq. (3) above, it follows that the partial derivative of $v$ with respect to the price attribute is simply the relevant coefficient from the estimated conditional logit model. In the case of fair trade coffee, this is the sum of the PRICE and the FTPRICE coefficients. The elasticities given in Table 3 were calculated on the basis of aggregated rather than individual choice probabilities, meaning that they can also be interpreted as a percentage change in the proportion of respondents who would purchase a given coffee variety. These were also calculated at the base price of $\$ 1.20$ per cup. No elasticities are reported for changes in the price of other coffee varieties as no price variations for the dark, flavored, and other coffees were observed (i.e., these prices were not discounted at any point in the experiment).

The results suggest, as mentioned above, that changes in own price have less of an effect on the purchase probability of the fair trade coffee than on the Colombian variety. As the price of the Colombian variety increases, consumers would be quick to switch to other, cheaper types of coffee. Purchasers of fair trade coffee, however, are much less price responsive, and would not switch coffee types as readily. This is further supported by the low cross-price elasticities for Colombian and other coffees as the price of fair trade coffee increases. Furthermore, joint significance tests of the two price coefficients indicate that the net price effect on fair trade coffee is not significantly different from zero. In short, while the fair trade coffee drinkers in our sample were significantly less price responsive than the drinkers of conventional coffee, the proportion of purchasers "abandoning" the fair trade product would be low if price increased. This agrees with observations by the vendor's staff that there is a segment of consumers who are loyal purchasers of fair trade products at campus outlets.

Larson (2003) notes that the own-price elasticities for coffee as a commodity are widely accepted to be very low. Furthermore, Krishnamurthi and Raj (1991) and Bell et al (1999) find that price elasticities for individual brands of coffee are very elastic, ranging in magnitude from -1.0 to -14.8 . In the context of these previous studies, our findings suggest that the consumers in our study who purchase fair trade products view it 
more as a distinct product category than merely as a favored brand of traditional coffee products.

Our findings, especially the near-zero own-price elasticity for fair trade coffee, imply that the retailer could increase revenues by increasing the price of fair trade coffee on campus. In conversations with the vendor, it became clear that despite higher costs for the fair trade coffee beans, there was little interest in capturing a potential market premium (Ould 2004). Instead, the vendor charged the same price for all coffee types at his campus establishments. This apparently stems from an ideological belief that students (who form a substantial component of the customer base) should be able to support fair trade products at no additional cost.

\section{CONCLUSION}

Coffee is the most popular fair trade product in Canada, and a sizable portion of consumer coffee expenditures go to products prepared away from home. For many consumers, speciality brewed coffee vendors are likely to be the most visible venues for fair trade products. Direct observation of consumer behavior in brewed coffee establishments would therefore appear to be an ideal method for investigating ethical consumerism. Despite this, little economic research has focused on the market for brewed coffees. One reason for this may be the difficulty of finding vendors who are willing to cooperate with research that requires changing the prices presented to their customers.

In this study, we were able to work with a vendor to implement an experimental design in an actual market setting. This design enabled consumers to reveal their preferences for cups of freshly brewed coffees, of which fair trade was one of the varieties. The results show that fair trade coffee exhibits a lower own-price elasticity than similar conventional products. Furthermore, conventional coffee varieties do not see a large increase in their proportion of buyers as the price of fair trade increases. These findings suggest that ethical attributes may be the primary influence on coffee purchasing behavior for most consumers of fair trade coffee. These purchasers were presumably driven more by a desire to consume socially responsible products and may not be motivated by price.

Studies have shown that ethical consumption choices can be influenced by price and convenience (e.g., Browne et al 2000). Bird and Hughes (1997) describe three levels of ethical consumers. The first is motivated primarily by moral values and will make tradeoffs between traditional product benefits and ethical characteristics of products. A second type of consumer is primarily motivated by quality and brand names. If they purchase an ethical good because of its performance, the "ethicalness" of that product is an added bonus. While they may be hesitant to believe the ethical claims of a product, they can often be persuaded to purchase these goods. The third type of consumer is selfish and cannot easily be persuaded to buy ethical goods; rather, they are driven only by price and traditional quality concerns.

The results of our study could be considered consistent with this categorization of consumers. We observed that the proportion of consumers purchasing fair trade coffee, although relatively small in size, is unresponsive to own price changes, suggesting that the bulk of these consumers are basing their decisions on attributes other than price. As the relative price of conventional coffee increased, consumers of these products, who were the largest segment of the coffee market we examined, appear willing to switch to fair 
trade coffee. We would hypothesize that this consumer segment consists largely of the "selfish" consumers posed by Bird and Hughes (1997). Ideally, this could be investigated more fully with a richer data set that would allow for the application of techniques, such as finite mixture models, that better capture consumer heterogeneity. Information on individual consumer attitudes and motivations regarding socially responsible products, not available in our study, would be necessary to shed more light on the dimensions of ethical consumerism.

This study is apparently the first to examine fair trade purchase behavior in an actual market setting. It is also the only study we could locate on freshly brewed coffee products, which is surprising given the product's popularity. The demonstration that fair trade coffee exhibits low sensitivity to price suggests that the market premiums identified by previous stated preference studies do indeed exist and are not merely artifacts of hypothetical settings. Future research should revisit this analysis in a broader variety of market settings to examine whether university students and staff, who may be more aware of fair trade issues, hold preferences for fair trade coffee that are typical of all coffee consumers. Furthermore, similar in-store experiments could be used to validate the price premiums estimated through hypothetical methods in previous studies in a variety of product areas.

\section{NOTE}

${ }^{1}$ Note that the proportion of the "other" coffee purchases is the sum of the dark $(0.191)$, light (0.089), and flavored (0.115) coffee varieties.

\section{ACKNOWLEDGMENTS}

This research was supported in part by a grant from the Faculty of Agriculture, Forestry, and Home Economics at the University of Alberta. The authors acknowledge the contributions of Wendy Wismer and the students of ENCS 410 (Winter 2004). Special thanks to Michael Ould and his staff at Java Jive for allowing us to conduct this experiment at his establishment.

\section{REFERENCES}

Anderson, R. C. and E. N. Hansen. 2004. Determining consumer preferences for ecolabelled forest products. Journal of Forestry 102: 28-32.

Bacon, C. 2005. Confronting the coffee crisis: Can fair trade, organic, and specialty coffees reduce small-scale farmer vulnerability in northern Nicaragua? World Development 33: 497-511.

Bell, D. R., J. Chiang and V. Padmanabhan. 1999. The decomposition of promotional response: An empirical generalization. Marketing Science 18: 504-26.

Ben-Akiva, M. and S. R. Lerman. 1985. Discrete Choice Analysis: Theory and Application to Travel Demand. Cambridge: MIT Press.

Bird, K. and D. R. Hughes. 1997. Ethical consumerism: The case of "fairly-traded" coffee. Business Ethics: A European Review 6: 159-67.

Bjorner, T. B., L. G. Hansen and C. S. Russell. 2004. Environmental labeling and consumers' choiceAn empirical analysis of the effect of the Nordic Swan. Journal of Environmental Economics and Management 47: 411-24.

Browne, A. W., P. J. Harris, A. H. Hofny-Collins, N. Pasiecznik and R. R. Wallace. 2000. Organic production and ethical trade: Definition, practice and links. Food Policy 25: 69-89. 
Fair Trade Federation. 2004. Fair Trade Facts. Available at http://www.fairtradefederation.com/ ab_facts.html (accessed April 25, 2004).

Greene, W. H. 2002. LIMDEP Version 8.0. Plainview, New York: Econometric Software, Inc.

International Coffee Organization. 2005. ICO Indicator Prices: Monthly and Annual Averages. Available at http://www.ico.org/prices/p2.htm (accessed August 11, 2005).

Krishnamurthi, S. P. R. and S. P. Raj 1991. An empirical analysis of the relationship between brand loyalty and consumer price elasticity. Marketing Science 10: 172-83.

Larson, B. 2003. Eco-labels for credence attributes: The case of shade grown coffee. Environment and Development Economics 8: 529-47.

Loureiro, M. L. and J. Lotade. 2005. Do fair trade and eco-labeling in coffee wake up the consumer conscience? Ecological Economics 53: 129-38.

Maddala, G. 1983. Limited-Dependent and Qualitative Variables in Econometrics. Cambridge: Cambridge University Press.

McFadden, D. 1974. Conditional logit analysis of qualitative choice behaviour. In Frontiers in Econometrics, edited by P. Zarembka, pp. 105-42. New York: Academic Press.

Ould, M. 2004. Personal communication with authors.

Pelsmacker, P., L. Driesen and G. Rayp. 2005. Do consumers care about ethics? Willingness to pay for fair-trade coffee. Journal of Consumer Affairs 39: 363-85.

Ponte, S. 2002. The 'latte revolution'? Regulations, markets and the consumption in the global coffee chain. World Development 30: 1099-122.

Raunolds, L. T. 2000. Re-embedding global agriculture: The international organic and fair trade movements. Agriculture and Human Values 17: 297-309.

Train, K. E. 2003. Discrete Choice Methods with Simulation. Cambridge: Cambridge University Press.

TransFair Canada. 2005. Current Statistics. Available at http://www.transfair.ca/en/ mediaresearchers/stats (accessed March 12, 2005). 